Research Article

\title{
Cloning and expression of embryogenesis-regulating genes in Araucaria angustifolia (Bert.) O. Kuntze (Brazilian Pine)
}

\author{
Paulo Sérgio Schlögl ${ }^{1}$, André Luis Wendt dos Santos ${ }^{2}$, Leila do Nascimento Vieira ${ }^{1}$, \\ Eny Iochevet Segal Floh ${ }^{2}$ and Miguel Pedro Guerra ${ }^{1}$ \\ ${ }^{1}$ Laboratório de Fisiologia do Desenvolvimento e Genética Vegetal, Departamento de Fitotecnia, \\ Universidade Federal de Santa Catarina, Florianópolis, SC, Brazil. \\ ${ }^{2}$ Laboratório de Biologia Celular Plantas, Departamento de Botânica, Universidade de São Paulo, \\ São Paulo, SP, Brazil.
}

\begin{abstract}
Angiosperm and gymnosperm plants evolved from a common ancestor about 300 million years ago. Apart from morphological and structural differences in embryogenesis and seed origin, a set of embryogenesis-regulating genes and the molecular mechanisms involved in embryo development seem to have been conserved alike in both taxa. Few studies have covered molecular aspects of embryogenesis in the Brazilian pine, the only economically important native conifer in Brazil. Thus eight embryogenesis-regulating genes, viz., ARGONAUTE 1, CUP-SHAPED COTYLEDON 1, WUSCHEL-related WOX, S-LOCUS LECTIN PROTEIN KINASE, SCARECROW-like, VICILIN 7S, LEAFY COTYLEDON 1, and REVERSIBLE GLYCOSYLATED POLYPEPTIDE 1, were analyzed through semiquantitative RT-PCR during embryo development and germination. All the eight were found to be differentially expressed in the various developmental stages of zygotic embryos, seeds and seedling tissues. To our knowledge, this is the first report on embryogenesis-regulating gene expression in members of the Araucariaceae family, as well as in plants with recalcitrant seeds.
\end{abstract}

Key words: seed development, Brazilian Pine, embryogenesis-regulating genes, zygotic embryogenesis.

Received: March 18, 2011; Accepted: August 27, 2011.

\section{Introduction}

Araucariaceae is one of the most ancient families of gymnosperms. With origins dating back to the Triassic, the family expanded and diversified in the northern and southern hemispheres until the end of the Cenozoic (Kershaw and Wagstaff, 2001). The present restriction to the southern hemisphere alone (Setoguchi et al., 1998) is probably a consequence of angiosperm development in the MidCretaceous. Through the widespread and uncontrolled exploitation of several species for timber, food and ornamental purposes, many are currently considered threatened or endangered.

Araucaria angustifolia, the Brazilian pine, is the only naturally occurring member of this family in Brazil. Until the 1970's, it was the most exploited local timber-source, with the consequential marked depletion of natural populations (Guerra et al., 2000). Nowadays, the priorities set by the Brazilian environmental authorities include conserva-

Send correspondence to Miguel Pedro Guerra. Programa de Pós Graduação em Recursos Genéticos Vegetais, Laboratório de Fisiologia do Desenvolvimento e Genética Vegetal, Universidade Federal de Santa Catarina, 88040-900 Florianópolis, SC, Brazil. E-mail: mpguerra@cca.ufsc.br. tion of natural remnants and the establishment of breeding programs for the reforestation of exploited areas.

Within this scenario, biotechnological approaches designed to improve somatic embryogenesis, such as the in vitro formation of embryos, could potentially pave the way to the development of efficient genetic improvement and germoplasm conservation methods for the Brazilian pine. Although protocols for plant regeneration by somatic embryogenesis have already been obtained for a few conifer species, no such method has been specifically developed in this case, since many of the problems encountered, especially the asynchronous development and misshaping of mature somatic embryos, can be attributed to the suboptimal conditions used in culture-media. Thus, before starting an investigation, a deeper understanding of the molecular, biochemical, and physiological processes involved during seed development, is a basic requirement (Stasolla et al., 2003), as knowledge thereof could aid in the development of more precise and less empirically based protocols for this specific case (dos Santos et al., 2002).

Seed development can be divided into two phases. In the first, embryo morphogenesis takes place, with the correct establishment of the body plan and the arrangement of 
cell-types within each tissue of the embryo. It has been shown that, during the second phase (maturation), besides the several signaling pathways integrating information from genetic programs, hormonal and metabolic signals are also required to prepare the embryo for subsequent desiccation and dormancy, as well as to accumulate the necessary nutrients for initial seedling growth (Gutierrez et al., 2007).

When compared to other conifer species, the Brazilian pine reveals unique early zygotic embryogenesis features with a high degree of specialization (Buchholz, 1920; Kaur and Bhatnagar, 1983). Furthermore, the seeds themselves are recalcitrant and mostly orthodox (Attree and Fowke, 1993). Despite recent reports on the accumulation of proteins and abscisic acid (Silveira et al., 2008), as well as polyamines and amino acids (Astarita et al., 2003, 2004), during embryogenesis, nothing has been published so far on gene expression during seed development, not only as regards this species itself, but also other members of the Araucariaceae family as a whole.

Besides the available plant-genome sequences and EST databases, genetic manipulation and the occurrence of mutants also provide a framework for gene expression analysis of embryogenesis in uncharacterized plant species. As angiosperm and gymnosperm plants evolved from a common ancestor around 300 million years ago, subsequent mutual differences in cell anatomy and molecular biology of embryogenesis have obviously been reported to occur (Bowe et al. 2000; Cairney et al., 2006; Cairney and Pullman, 2007). Nevertheless, molecular analysis of embryo development in various plant species has revealed that several mutually identical developmental pathways seem to have been maintained. Of the SeedGene database list of the 295 genes that are essential for embryogenesis in Arabidopsis, approximately $72 \%$ are to be found in the proteome (Cairney and Pullman, 2007). There is ample evidence that transcription factors play a role in those functional polymorphisms affecting growth and development in the different species. Approximately half of the nucleotide polymorphisms account for various phenotypes that occur in regulatory regions (Alonso-Blanco et al. 2005). Thus, the resemblance of most coding sequences for embryoexpressed genes in conifers to those in other plants is not surprising (Cairney and Pullman, 2007).

Prior studies of angiosperms have identified some of the molecular components required for forming and maintaining shoot apical (SAM) and root apical (RAM) meristems. The development of both requires the interaction of gene regulatory networks, including ZWILLE (ZLL), ARGONAUTE1 (AGOI), NO APICAL MERISTEM (CUC1-3), WUSCHEL (WUS), CLAVATA1 (CLV1), SCARECROW (SCR) and others. As yet, the Brazilian pine genome has not been sequenced, the few genes so far characterized during seed development having presented similarities with those found in other conifer genomes and Arabidopsis. A leucine-rich-repeat trans-membrane pro- tein that resembles CLAVATA 1 was shown to be expressed during embryo development in this species, thereby implying that some original embryogenesis-regulating mechanisms have been conserved in the Araucariaceae family (Fernandez HJ (2001) PhD Thesis, Universidade Estadual de Campinas, Campinas, SP, Brazil).

In order to increase current knowledge embryonic gene expression and establish molecular markers for monitoring normal development and/or the detection of abnormalities early in the somatic embryogenesis process, semiquantitative RT-PCRs (sqRT-PCR) were used in the present study in the analysis of eight embryogenesis-regulating genes, viz., ARGONAUTE 1, CUP-SHAPED COTYLEDON 1, WUSCHEL-related WOX, S-LOCUS LECTIN PROTEIN KINASE, SCARECROW 1, VICILIN 7S, LEAFY COTYLEDON 1 , and REVERSIBLE GLYCOSYLATED POLYPEPTIDE, during seed development in the Brazilian pine. Sequence alignment and phylogenetic reconstruction indicated, not only the shared sequential similarity between angiosperm and gymnosperms species, but also that many embryogenesis-regulating genes have been conserved in both taxa throughout their evolution. In addition, all of the eight selected genes were differentially expressed during zygotic embryo development.

\section{Materials}

\section{Plant growth}

Seeds were harvested in Santa Catarina State $\left(27^{\circ} 47^{\prime} \mathrm{S}\right.$, 49²9' W), Brazil, from December, 2007 to May, 2008, whereupon, embryos at the late globular (Gl), cotyledonary (Co) and mature (Ma) stages were isolated. Due to the very low amount and small size, pro-embryos and early globular stages were excluded from the analysis. In vitro seed germination was carried out on basic medium BM basal salts (Gupta and Pullman, 1991), supplemented with 3\% (w/v) saccharose and $0.65 \%(\mathrm{w} / \mathrm{v})$ agar, under a $16 / 8$ (light/dark) photoperiod, at $25 \pm 2{ }^{\circ} \mathrm{C}$. Five days after germination, seedling roots and needles were detached, individually weighed and frozen in liquid nitrogen, for subsequent RNA isolation.

\section{Total RNA isolation}

Total RNA from late globular and cotyledonary zygotic embryos (200 mg fresh weight) were extracted with Trizol $^{\circledR}$ (Invitrogen, Carlsbad, CA) according to manufacturer's protocol. RNA from mature zygotic embryos, megagametophytes, needles and roots (150-200 mg fresh weight) were extracted as previously described (Preccott and Martim, 1987). RNA quality was monitored by electrophoresis on $1 \%(\mathrm{w} / \mathrm{v})$ formaldehyde agarose gels, followed by ethidium bromide staining.

\section{Degenerated primer design}

Query sequences, comprising full-length Arabidopsis gene-sequences of each selected gene, were used for 
screening the NCBI database to find homologous cDNAs from various plant species for posterior alignment with Clustal X software (Thompson et al., 1997). The degenerated primers were manually designed, based on the aligned nucleotide sequences thus obtained.

\section{cDNA synthesis, cloning and sequencing}

cDNA of each plant was synthesized by using $2 \mu \mathrm{g}$ of total RNA digested with DNase I (Fermentas, USA), $500 \mathrm{ng}$ of oligo-d $\mathrm{d}_{25}$-ancored primer (5'-T(25) VN-3'), and the High Capacity cDNA Reverse Transcription kit (Applied Biosystems, USA), in a $20 \mu \mathrm{L}$ reaction, according to the manufacturers' instructions.

cDNA templates were amplified by PCR, using degenerated primers designed in compliance to the sequences of the selected genes (Table 1). According to nucleotide alignment, cDNA fragments of the expected size were cloned into a TA vector (Invitrogen, Carlsbad, CA), for posterior sequencing with the ABI PRISM Dye Terminator Cycle Sequencing Ready Reaction Kit (Perkin Elmer, Alameda, CA) and M13 universal primers.

In order to confirm the identitity of cDNA cloned sequences, each was compared to DNA sequence databases, using BLAST search tools (Altschul et al., 1997). For phylogenetic analysis, deduced protein sequences were aligned using the Clustal X program (Thompson et al., 1997). Phylogenetic and molecular evolutionary analyses were with selected sequences using the MEGA program, version 4 (Tamura et al., 2007). Bootstrap analysis was with 1000 replicates. Generic naming of sequences was according to the denomination of the selected gene used to design the degenerated primer, plus the " $A a$ " prefix, e.g., AaWOX.

\section{Semi-quantitative RT-PCR analysis}

Semi-quantitative RT-PCR (sqRT-PCR) analysis was to check expression patterns of the selected genes during zygotic embryogenesis and early embryo germination. The design of appropriate primers was based on previously described specific nucleotide sequences of Brazilian pine cDNA fragments. The sequences thus obtained were analyzed by way of Primer 3.0 version 0.4 .0 software, with CG Clamp set as 1 or 2 . The primer sequences are listed in Table 2. PCR amplifications were carried out to test annealing temperatures, primers and the optimal number of PCR cycles for each of the selected primers (Table 2). Template cDNAs were synthesized as previously described, and dilutions adjusted, with Ubiquitin-1 (AaUBI-1, GW924714) as an endogenous normalization factor.

The following thermal cycle conditions were used for the sqRT-PCR reactions: $94{ }^{\circ} \mathrm{C}$ for $3 \mathrm{~min}$, followed by $94{ }^{\circ} \mathrm{C}$ for $30 \mathrm{~s}$, a $30 \mathrm{~s}$ annealing cycle of each pair of primers, and a 1 min cycle at $72{ }^{\circ} \mathrm{C}$, followed by the respective number cycles for each specific pair of primers and an final 5 min elongation step at $72{ }^{\circ} \mathrm{C}$. The PCR reactions were carried out in a final volume of $25 \mu \mathrm{L}$, containing $0.3 \mu \mathrm{M}$ of primers and $2 \mu \mathrm{L}$ of cDNA template. The mean length of PCR products ranged from 175 to $200 \mathrm{bp}$. PCR products, first resolved on $2 \%(\mathrm{w} / \mathrm{v})$ agarose gels stained with ethidium bromide, were then photo-documented.

sqRT-PCR reactions were carried out in three replicates from total RNA originating from two different biological experiments. An aliquot of the total RNA digested with DNAse I to synthesize the cDNA template, was used as control in separate PCR reactions, to so check for genomic DNA contamination. No signals were obtained,

Table 1 - Homologous genes of angiosperm proteins associated to embryogenesis, and a list of degenerated primers used for cDNA isolation during zygotic embryogenesis and early-seedling growth in the Brazilian pine.

\begin{tabular}{|c|c|c|c|}
\hline Gene & Function & Primers & Size* \\
\hline CLAVATA 1 & Cell fate & $\begin{array}{l}\text { For 5'RTNGGNAWRGGNKSNNYNCC'3 } \\
\text { Rev 5'YKVGCVARNCCRAARTCDGC'3 }\end{array}$ & 236 \\
\hline WUSCHEL & Meristem maintenance & $\begin{array}{l}\text { For 5'ANNDGBHSVMGNTGGAMDCC'3 } \\
\text { Rev 5'GRGCYTTRTRRTTYTGRAAC'3 }\end{array}$ & 201 \\
\hline UBIQUITIN & Ubiquitination & $\begin{array}{l}\text { For 5'HGTBATHTTYGGNCCDGATG'3 } \\
\text { Rev 5'CTRWACADBCKDGCDGCTTC'3 }\end{array}$ & 270 \\
\hline LEAFY COTYLEDON 1 & Maturation & $\begin{array}{l}\text { For 5'YWBMTGCCVATHGCNAAYGT'3 } \\
\text { Rev 5'ATDGCCCANARVABRTCBTC'3 }\end{array}$ & 240 \\
\hline VICILIN $7 S^{\mathrm{a}}$ & Seed protein storage & Acess number $A A \mathrm{M} 81249.1$ & \\
\hline ARGONAUTE 1 & Meristem maintenance & $\begin{array}{l}\text { For 5'VAARMGNATWTGTGARACTG'3 } \\
\text { Rev 5'TGBCCYTCRCTDACWCCATC'3 }\end{array}$ & 480 \\
\hline SCARECROW & Cell fate and division & $\begin{array}{l}\text { For 5'VATHGAYYTNGACATMATGC'3 } \\
\text { Rev 5'RAGHARVSAVAGRTCYTTCC'3 }\end{array}$ & 725 \\
\hline CUPSHAPED COTYLEDON1 & Organ boundary & $\begin{array}{l}\text { For 5'SAACARRTSYGAGCCNTGGG'3 } \\
\text { Rev 5'VCKRTAYTCRYGCATNACCC'3 }\end{array}$ & 270 \\
\hline AUXIN BINDING POTEIN 1 & Auxin flux & $\begin{array}{l}\text { For 5'TGAARGAGRTDGARRTDTGG'3 } \\
\text { Rev 5'ARYYKBGCWGCWGTRTGDGG'3 }\end{array}$ & 250 \\
\hline
\end{tabular}

*PCR product sizes. ${ }^{\text {a }}$ Cloned in another work. 
Table 2 - sqRT-PCR primers, PCR product sizes, melting temperatures, and PCR cycle numbers used in the analysis of gene expression during zygotic embryogenesis and early seedling growth in the Brazilian pine.

\begin{tabular}{|c|c|c|c|c|}
\hline Gene & sqRT-PCR primers & $\mathrm{TM}\left({ }^{\circ} \mathrm{C}\right)$ & Cycle numbers & Product size (bp) \\
\hline$A a A G O$ & $\begin{array}{l}\text { for 5'TCAAGGTGGGTGGAAGAAAC'3 } \\
\text { rev 5'TCAATGATCTCTTGCCGATG'3 }\end{array}$ & 50 & 27 & 266 \\
\hline AaWOX & $\begin{array}{l}\text { for 5'GGCTTTGTGGTTTTGGAAC'3 } \\
\text { rev 5'GCCAAGCCAAACTCAACTTC'3 }\end{array}$ & 46 & 35 & 142 \\
\hline AaLecKIN & $\begin{array}{l}\text { for 5'AAGGTGCTGGACTGGAAGAC'3 } \\
\text { rev 5'CCACTTTGGGGCAGAAATC'3 }\end{array}$ & 50 & 35 & 151 \\
\hline$A a V I C$ & $\begin{array}{l}\text { for 5'GAGGAGACTCGCTACAGATGC'3 } \\
\text { rev 5'CTTCCATCGATTTCTCTTTCC'3 }\end{array}$ & 50 & 27 & 220 \\
\hline$A a C U C$ & $\begin{array}{l}\text { for 5'AAAATGGGGGAAAAGGAATG'3 } \\
\text { rev 5'GCATCACCCAGTTGGTCTTC'3 }\end{array}$ & 50 & 35 & 220 \\
\hline$A a U B I$ & $\begin{array}{l}\text { for 5'GTCGGATGTGTTTCATCCTAATG'3 } \\
\text { rev 5'CTTCTGGATTTGCAGGACTTG'3 }\end{array}$ & 50 & 27 & 160 \\
\hline AaLEC & $\begin{array}{l}\text { for 5'GCCGATTGCAAACGTGAG'3 } \\
\text { rev 5'TGATGGTCTTGCGCTTTTC'3 }\end{array}$ & 46 & 35 & 164 \\
\hline$A a R P G$ & $\begin{array}{l}\text { for 5'AGGGATGTTGAGCCACAAAC'3 } \\
\text { rev 5'CATTGATGACGATTGCTTCG'3 }\end{array}$ & 50 & 27 & 250 \\
\hline$A a S C R$ & $\begin{array}{l}\text { for 5'CTTTGCTCGGACCTTGAATC'3 } \\
\text { rev 5'TATTTGCATCGGAGCCTGTC'3 }\end{array}$ & 50 & 35 & 165 \\
\hline
\end{tabular}

thus indicating the absence of any detectable contamination (data not shown).

\section{Results}

Identification and sequencing analysis of embryogenesis-regulating genes

Fragments of eight embryogenesis-regulating genes related to morphogenesis, cell signalization, and reserve deposition (ARGONAUTE 1 (AaAGO-1), CUP-SHAPED COTYLEDON 1 (AaCUC), WUSCHEL-related WOX (AaWOX), S-LOCUS LECTIN PROTEIN KINASE (AaLecK), SCARECROW-like (AaSCR), REVERSIBLE GLYCOSYLATED POLYPEPTIDE 1 (AaRPG), LEAFY COTYLEDON 1 (AaLEC) and VICILIN 7S (AaVIC)) were isolated, cloned and sequenced from cDNA libraries of Brazilian pine embryonic cell cultures.

AaAGO 1 (GW924721) shared high-deduced amino acid sequence identity with not only putative $A G O 1$ homologues from Populus trichocarpa (97\%), but also with AGO1 and ZLL (ZWILLE) proteins from Arabidopsis (91\% and $89 \%$, respectively). Sequence alignment with plant $A G O$ proteins was to demonstrate the similarity among sequences from the different taxa (Figure 1). The cloned sequence from $A a A G O$ represented $15 \%$ of the full length $A G O 1$ sequence from Arabidopsis, and was shown to share high similarity within a region between the $P A Z$ and $P I W I$ domains (amino acid 693-851). In order to define $A a A \mathrm{GO}$ evolutionary relationships, alignments of deduced protein sequences of the $A G O$ protein family from Arabidopsis and other plants were used to construct an unrooted neighbor-joining phylogenetic tree. AaAGO,AGO1, ZLL and $A G O 5$ proteins from various plant species clustered to- gether in Clade I (Vaucheret, 2007), thereby forming a putative cluster of orthologues with $100 \%$ bootstrap support, thus implying that $A a A G O$ belongs to the $A G O 1$ subgroup (Figure 2).

The putative Brazilian pine CUC-like deduced protein (AaCUC-like, GW924718) was highly identical with both putative $N A C$ proteins from Solanum lycopersicum (92\%) and Populus trichocarpa (87\%), and CUC2 from Arabidopsis thaliana (92\%). The AaCUC-like sequence corresponded to $24 \%$ of the entire sequence (Aac 55-143), and covered $60 \%$ of the $N A C$ domain (subdomains N2-N4) of the Arabidopsis $C U C 2$ protein (Figure S1A).

The deduced AaWOX-like protein sequence (GW924719) presented appreciable similarity to a $W O X$ like protein from Picea sitchensis (94\%), Physcomitrella patens $(90 \%)$, and other related proteins from various plant species (Figure S1B). The protein sequence of AaWOX corresponded to $20 \%$ of the WOX13 protein from Arabidopsis (Aac 100-153). Hence, a phylogenetic tree was constructed using the alignment of $A a W O X$ and other plant protein sequences of the WUS/WOX family. It was observed that AaWOX clustered with WOX10-14 from Arabidopsis and WOX-like proteins from Populus tomentosa and Physcomitrella patens. This very close relationship to the Physcomitrella sequence possibly implies a very ancient common origin (Figure 3).

Three different sequences of RECEPTOR-like PROTEIN KINASES (RLKS) were cloned with the degenerated primer for the CLV1 cytoplasmatic kinase domain. According to BLAST search, AaRLK1 (AaLecKin, GW924722) was classified within the S-locus lectin protein kinase subfamily and AaRLK2 (AaCLVL, GW924723) - 3 (LRRPK, GW924717) as Leucine-Rich Repeat protein 


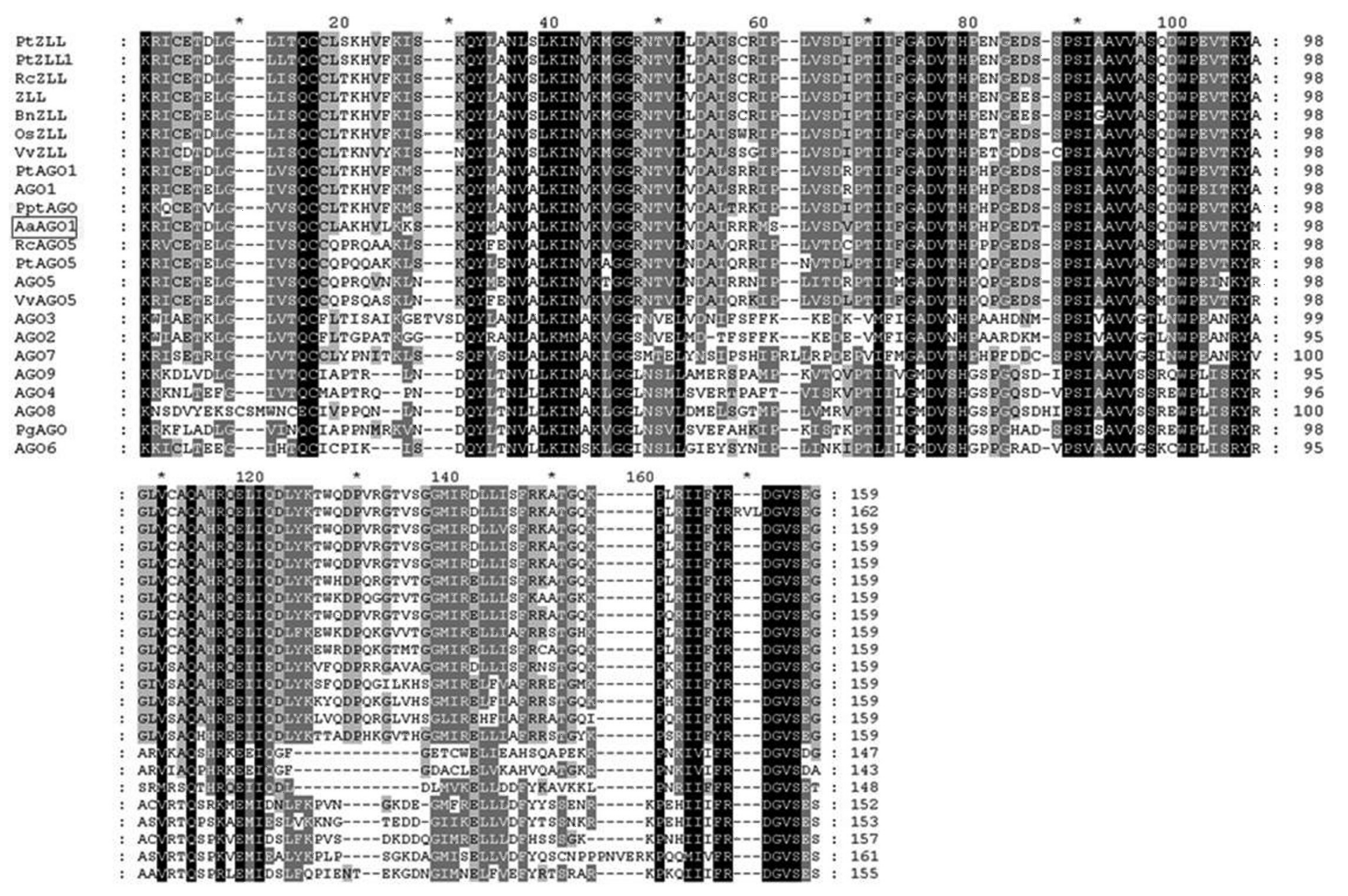

Figure 1 - Alignments of the plant ARGONAUTE protein family. Multiple alignments were done using ClustalW (version 1.74) software. Accession numbers: Arabidopsis thaliana - AGO1: NP_849784, AtAGO2: NP_174413, AtAGO3: NP_174414, AtAGO4: NP_565633, AtAGO5: Q9SJK3, AtAGO6: NP180853, AtAGO7: NP_177103, AtAGO8: NP_197602, AtAGO9: CAD66636, AtZLL: NP_199194. Populus trichocarpa - PtZLL: XP_002314663, PtZLL1: XP 002312555, PtAGO1: XP 002329692, PtAGO5: XP 002298162. Brassica napus - BnZLL: ABY52943. Vitis vinifera - VvZLL: XP-002281687, VvAGO5: XP_002271699. Physcomitrella patens - PptAGO1: XP_001757611. Ricinus communis - RcZLL: XP_002517060, RcAGO5: XP 002523757. Araucaria angustifolia - AaAGO: GW924721.

kinase CLV-like. From sequence alignment with different receptor-like protein kinase cytoplasmatic kinase domains (Figure S1C), it was deduced that, as with Arabidopsis and other plants, different subfamilies of receptor-like protein kinases participate in the process of cell signalization during Brazilian pine embryogenesis.

AaSCR (GW924716) presented $88 \%$ identity with a putative $S C R$ deduced protein sequence from Pinus sylvestris, and $83 \%$ with a putative $S C R$ protein from Populus trichocarpa. The deduced AaSCR sequence covered 16\% of the $S C R$ protein from Arabidopsis (amino acid 534-644), the alignment of protein sequences showing high conservation of the AaSCR protein and other plant SCRs (Figure S1D). The AaSCR sequence itself encompasses part of the PFYRE domain present in the C-terminal region of Arabidopsis SCRs (Pysh et al., 2009).

A putative AaLEC-like (CCAAT binding protein) sequence (GW924720) presented 80 amino acids sharing $100 \%$ similarity with a homologous protein from Vitis vinifera and Ricinus communis, besides covering $40 \%$ of the full length sequence of the Arabidopsis NF-YB3 binding factor. The alignment of LEC-like proteins demon- strated high AaLEC similarity to all the proteins analyzed, thereby inferring its role during embryo development (Figure S1E).

By using degenerate oligonucleotides based on the $A B P 1$ sequence, a putative reversible glycosylated polypeptide (RPG) was cloned (GW924715). The sequence covered 23\% of the full length of the Arabidopsis RPG 1 protein sequence (amino acid 71-153). Through being involved in the biosynthesis of various plant polysaccharides, such as hemicelullose and starch, there is evidence that $R P G$ proteins may play a role in cell-wall biosynthesis (Delgado et al., 1998). BLAST search and the alignment of $R P G$-like sequences demonstrated that AaRPG has high amino acid sequence conservation with other $R P G$ proteins from plants (Figure S1F).

\section{Expression of embryogenesis-regulating genes during zygotic embryogenesis and initial seedling growth}

Semiquantitative RT-PCR was applied in the analysis of selected embryogenesis-regulating gene expression during Brazilian pine embryo development and initial seedling growth (Table 1). Genes related to morphogenesis and cell 


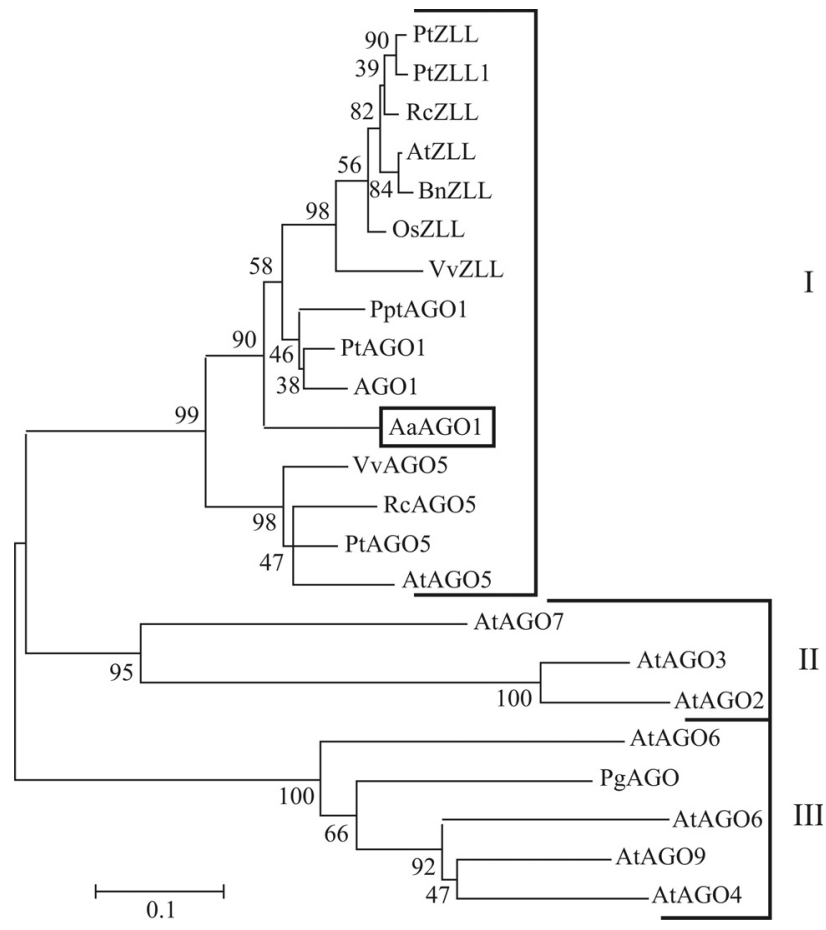

Figure 2 - Phylogenetic tree of ARGONAUTE proteins. Multiple alignments were done using ClustalW (version 1.74) software. MEGA software was used in bootstrap analysis and tree construction. Bootstrap percentages are indicated at each fork. Accession numbers: Arabidopsis thaliana - AGO1: NP 849784, AtAGO2: NP 174413, AtAGO3: NP_174414, AtAGO4: NP_565633, AtAGO5: Q9SJK3, AtAGO6: NP180853, AtAGO7: NP 177103, AtAGO8: NP 197602, AtAGO9: CAD66636, AtZLL: NP_199194. Populus trichocarpa - PtZLL: XP_002314663, PtZLL1: XP_002312555, PtAGO1: XP 002329692, PtAGO5: XP_002298162. Brassica napus - BnZLL: ABY52943. Vitis vinifera - VvZLL: XP-002281687, VvAGO5: XP_002271699. Physcomitrella patens - PptAGO1: XP_001757611. Ricinus communis RcZLL: XP_002517060, RcAGO5: XP_002523757. Araucaria angustifolia - $\bar{A} a A G O$ : GW924721.

signaling (AaAGO, AaCUC, AaWOX, AaLeckin, AaLEC, AaRPG-like), and to seed-storage reserve (AaVIC), were upregulated until the cotyledonary stage $(\mathrm{Co})$. Subsequently, their expression decreased in mature zygotic embryos (Ma). AaSCR levels, high in late globular zygotic embryos (Gl) and seedlings (G5), did not differ at the transcript phase during the $\mathrm{Co}$ and Ma stages (Figure 4). Although in mature megagametophytes, $A a A G O$ was weakly expressed, $A a C U C$, $A a W O X, A a R P G$ and $A a V I C$ were highly so.

On considering the entire seedling and except for $A a S C R$, genes related to morphogenesis and cell signalization were upregulated, when compared to the Ma stage. AaVIC could not be detected in seedlings, isolated needles or roots. In isolated roots, there was little sign of $A a A G O, A a S C R$, and $A a L E C$, the contrary to AaCUC, AaWOX, and AaRPG (Figure 4). Whereas AaLecK was barely detected in isolated needles, the remaining genes were very much so (Figure 5).

\section{Discussion}

The existence of several pine-embryo EST collections containing mRNA sequences from related genes (Cai-

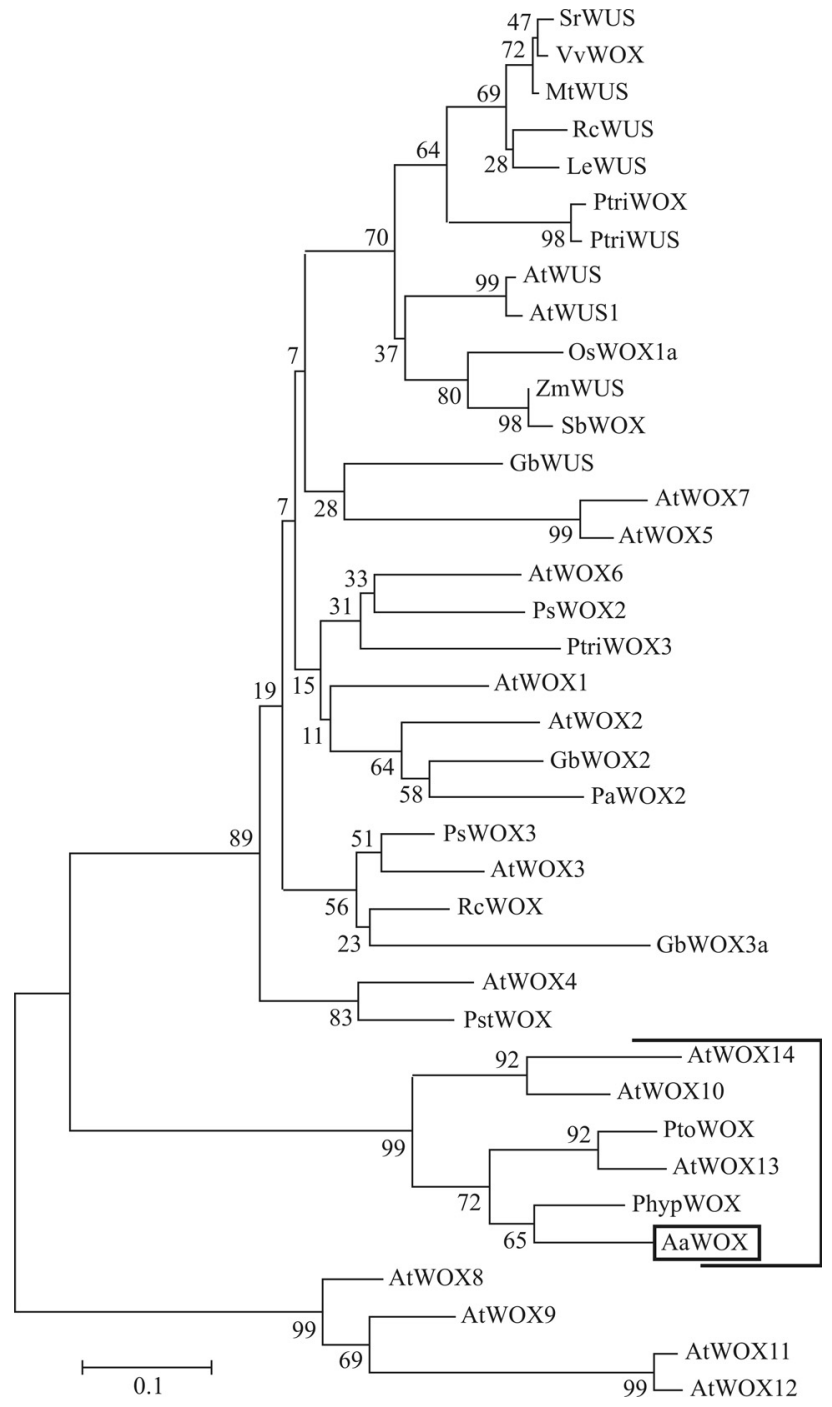

Figure 3 - Phylogenetic tree of WOX proteins. Multiple alignments were done using ClustalW (version 1.74) software. MEGA software was used in bootstrap analysis and tree construction. Bootstrap percentages are indicated at each fork. Accession numbers: Arabidopsis thaliana - AtWOX1: Q6X7K0, AtWOX2: Q6X7K1, AtWOX3: Q9SIB4, AtWOX4: Q6X7J9, AtWOX5: AAP37136, AtWOX6: Q9ZVF5, AtWOX7: Q9FFK0, AtWOX8: Q6X7J5, AtWOX9: Q6X7J4, AtWOX10: Q9LM83, AtWOX11: Q6X7J3, AtWOX12: Q8GY25, AtWOX13: O81788; AtWOX14: Q9LM84. Oryza sativa: OsWOX1a: Q7XM13. Streptocarpus rexii - SrWUS: B2WSTO. Vitis vinifera - VvWOX: XP_002266323. Medicago truncatula - MtWUS: ACK77479. Ricinus communis - RcWUS: XP_002530735, RcWOX: XP 002532820. Populus trichocarpa - PtriW̄OX: XP 002327757, PtriWUS1: A0AAS8, PtriWOX3:B9HW56. Zea mays - ZmWUS: NP 001105960. Sorghum bicolor - SbWOX: XP 002448707. Ginkgo biloba - GbWUS: CAT02906, GbWOX2: CAT02902, GbWOX3a: C3W868. Pinus sylvestrys - PsWOX2: C3W8A3-1, PsWOX3: C3W8A1. Picea sitchensis - PstWOX: B8LN48. Picea abies - PaWOX2: Q14FJ6. Populus tomentosa - PtoWOX: AAR83341. Physcomitrella patens PhyWOX: XP_001777634. Araucaria angustifolia - AaWOX: GW924719.

rney and Pullman, 2007), and the cloning of the putative homologous cDNAs of these genes in the Brazilian pine, together confirm that like mechanisms govern meristem activity and embryo maturation in gymnosperms as a whole. A putative ARGONAUTE 1 ( $A a A G O)$ was expressed and 


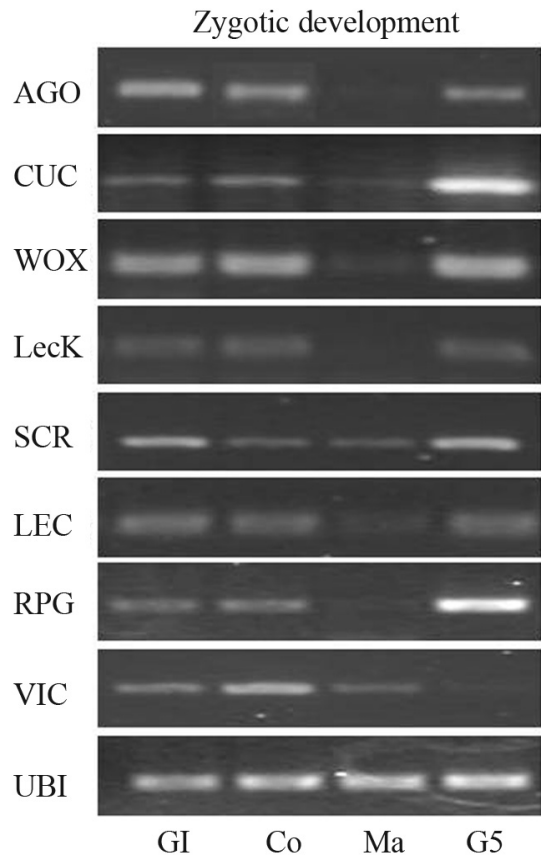

Figure 4 - Expression pattern of embryogenesis-regulating genes (ARGONAUTE $(A a A G O)$, CUP-SHAPED COTYLEDON1 ( $A a C U C)$, wushel-related WOX (AaWOX), S-locus lectin protein kinase (AaLecK), SCARECROW-like (AaSCR), VICILIN 7S (AaVIC), LEAFY COTYLEDON 1 (AaLEC), and a Reversible glycosylated polypeptide $(A a R G P))$ during Brazilian pine zygotic embryogenesis. RT-PCR reactions were carried out on reverse-transcribed total RNA samples from late globular (Gl), cotyledonary (Co) and mature zygotic embryos (Ma), and mature embryos (G5) after five days of germination. AaUBI-1 cDNA was used as endogenous normalization factor.

up-regulated during Brazilian pine early zygotic development and maturation, initial seedling growth (needles and roots) and in mature megagametophytes. Likewise, an ARGONAUTE (PgAGO) was shown to be up-regulated during meristem formation in the early stages of embryo development in Picea glauca (Tahir et al., 2006). As $P g A G O$ expression was reportedly restricted to the meristematic cells of both roots and shoots, it was assumed that $A G O$ is required for proper embryo development through the specification of stem-fate identity in these cells (Tahir et al., 2006). AGO1 and ZLL, the closest homologues to the $A G O 1$ protein family, participate in meristem formation, stem-cell fate, and leaf polarity through RNA silencing mechanisms (Lynn et al., 1999; Carmell et al., 2002). The protein sequence similarity with Arabidopsis ( $A G O 1$ and $Z L L$ ) and other plant $A G O 1$ proteins - in addition to the pattern of $A a A G O$ expression - gives to understand that similar mechanisms are capable of regulating SAM formation during early zygotic development and initial seedling development in the Brazilian pine (Figure 4). $A a A G O$ was also expressed in mature megagametophytes, thereby indicating the existence of a putative role for $A G O$ proteins during seed development in this gymnosperm (Figure 5).

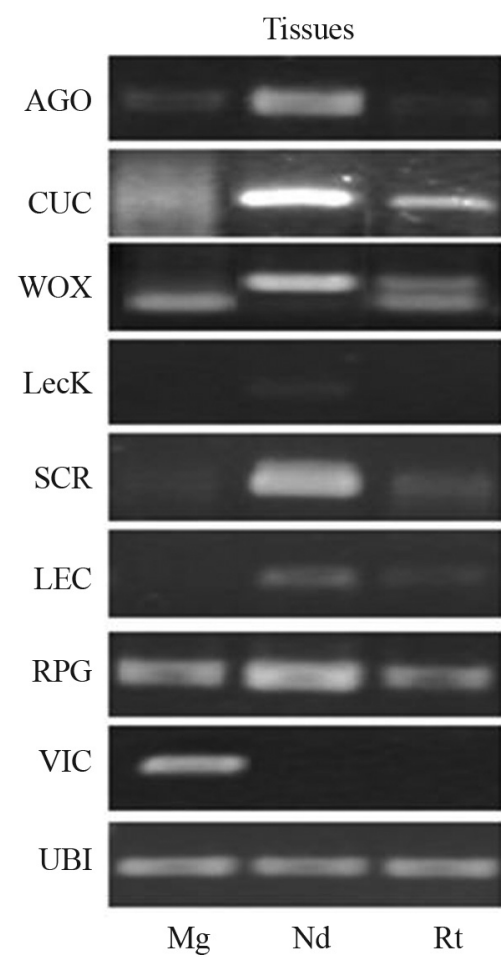

Figure 5 - Expression of embryogenesis-regulating genes (ARGONAUTE ( $A a A G O)$, CUP-SHAPED COTYLEDON1 ( $A a C U C$ ), wushel-related WOX (AaWOX), S-locus lectin protein kinase (AaLecK), SCARECROW-like (AaSCR), VICILIN 7S (AaVIC), LEAFY COTYLEDON 1 (AaLEC), and a Reversible glycosylated polypeptide $(A a R G P))$ in young seedling tissues and mature megagamethophytes in the Brazilian pine. RT-PCR reactions were carried out on reverse-transcribed total RNA samples from different tissues: $(\mathrm{Mg})$ mature megagametophytes, $(\mathrm{Nd})$ needles and (Rt) roots. AaUBI-1 cDNA was used as an endogenous normalization factor.

Development of a specific body-plan during embryogenesis requires the coordination of cell fates according to their individual position along embryo axes. A constant stem-cell population indicates that the recruitment of cells into new organs is precisely balanced by the formation of new stem-cell derivatives (Nardmann et al., 2009). These cells are located in stem-cell niches, where signals from the neighboring cells keep them in a pluripotent state. Their undifferentiated state is maintained by signals that depend upon WUS expression in a small underlying cell group termed the "organizing center" (OC) (Mayer et al., 1998). In turn, stem cells express CLAVATA3 (CLV3), which acts by restricting $W U S$ transcription via $C L V 1 / C L V 2$ signaling. This feedback provides a mechanism for controlling the size of the stem-cell pool (Schoof et al., 2000).

In the present work, a putative member of the WOX family $(A a W O X)$ and three different classes of leucine-rich receptor-like protein kinases, were cloned. In all, gene expression was analyzed, both during the period preceding cotyledon elongation, and in seedling roots and needles (Figures 4 and 5). Phylogenetic analysis of AaWOX showed it to belong to a putative cluster of orthologous genes, together with Arabidopsis WOX10-14, and a WOX-like pro- 
tein from both Populus tomentosa and Physcomitrella patens, a possible indication that this branch of the WOX protein-family is of ancient origin (Figure 3). Several members of the WOX family are expressed early during embryo development, and at low levels in vegetative tissues. In Picea glauca, PaWOX2 expression was observed in hypocotyls, apical shoots, and cotyledons, but not in roots (Palovaara and Hakman, 2008). In Arabidopsis thaliana, WOX5 expressed early during embryogenesis, appears to exert a function in RAMs during stem-cell signaling, analogous to that of WUS in SAMs (Sarkar et al., 2007), whereas other WOX proteins seem to play more diverse roles in cotyledon and cell division in embryos and suspensors (Wu et al., 2007). The results obtained in the present study attribute a putative role to AaWOX in functions associated with the regulation of cell division and/or differentiation during embryogenesis and initial seedling growth in the Brazilian pine.

Through BLAST analysis, three receptor-like protein kinases, cloned in the Brazilian pine, were placed into two RLK subgroups. AaRLK2-3 was classified as a putative leucine-rich repeat transmembrane CLV-like protein kinase (CLVL and LRRKS), and AaLecKin as a putative $\mathrm{S}$-locus lectin protein kinase. Some cDNAs, homologues to the receptor kinase CLAVATA1 (CLV1) and the receptor-like protein CLAVATA2 (CLV2), were encountered in pine embryo-derived EST-sequences (Cairney et al., 2006). Taken together, these results indicate that the main factors pertaining to the $C L V / W U S$ negative feedback loop are present in conifers, and that AaRLK2-3 might be acting together with AaWUS-like in the regulation of meristem maintenance. AaLecKin was expressed at low levels during all the stages of zygotic embryogenesis that were analyzed (Figure 3). S-locus lectin protein kinases (lectin RLKs) form a large family of receptor-like kinases with an extracellular legume lectin-like domain that is presumed to be involved in carbohydrate binding activities. Legume lectins are well-known carbohydrate-binding proteins, some members of this family having been shown to be involved in plant development (Wu et al., 2007; Wan et al., 2008). Therefore, it is possible that AaLecKin, as with other LecKinases (van Hengel et al., 2002), plays a connecting role in embryogenesis by perceiving the oligosaccharide signal generated in the early stages of embryogenesis, thereby ensuring correct embryo development.

The cotyledon boundary is crucial for postembryonic development during seed formation. The CUP-SHAPED COTYLEDON (CUC) transcription factors are central regulators of organ boundary structuring in plants, and play a decisive role in the establishment of meristems, through activation of the SHOOT MERISTEMLESS (STM) gene during embryogenesis (Takada et al., 2001). Of the several factors that have been reported to affect $C U C$ gene expression, auxin plays a major role in determining the respective spatial patterns. It is supposed that, together with auxin, miR164c mainly controls the accumulation of $C U C 1$ and
CUC2 and boundary morphogenesis (Aida and Tanaka 2006). Considering, both the high similarity of $A a C U C$ to other $C U C$ genes and its expression profile in the Brazilian pine during zygotic embryogenesis and in postembryonic organs, it is possible to suppose that it has developed a similar function to that observed in the other $C U C$ genes in model plants, such as Arabidopsis.

In the present study, a putative $A a S C R$ was expressed, both at the start of embryo development, and in postembryogenic structures (Figures 4 and 5). In Arabidopsis, $S C R$ encodes a putative transcription factor that belongs to the GRAS family. Radial patterning during embryogenesis and post embryonic development are regulated by SCARECROW (SCR) in both roots and shoots in Arabidopsis (Di Laurenzio et al., 1996). In maize and Arabidopsis, SCR expression has been observed during the early stages of embryogenesis, thereby implying that radial pattern formation is an early event in both species (Lim et al., 2000). AaSCR expression was up-regulated during the globular stage, after five days of embryo germination, and in seedling tissues (Figures 4 and 5). Taken together, members of the GRAS family probably play crucial roles in embryo and seedling development in the Brazilian pine.

The AaLEC-like sequence was very similar to that of another $L E C$, during protein alignment (Figure S1E). Moreover, its expression was slightly up-regulated during the first two phases of embryo development (globular and cotyledonary) (Figure 4). In $A$. thaliana, three $L E C$ genes (LEC1-2 and FUS3) are predominantly expressed during embryogenesis, thereby maintaining embryonic cell fate and specifying cotyledon identity (Braybrook and Harada, 2008). Other Arabidopsis LEC-like proteins are expressed at low levels in vegetative organs (Kwong et al., 2003). In the specific case of $A a L E C$, this was found to be expressed in needles and roots (Figure 5). In addition to its importance during embryo morphogenesis, AaLec is involved in the regulation of Vicilin accumulation, the main storage protein in the Brazilian pine, the same way as $L E C 1$ regulates protein accumulation and embryo maturation in Arabidopsis. The ectopic expression of LECl demonstrated that seed-storage-protein gene expression is controlled by LEC1 through the regulation of $A B I 3$ and FUS3 expression (Gutierrez et al., 2007). The expression of AaVicilin transcripts coincides with the first peak of abscisic acid accumulation during seed development in the Brazilian pine. ABA levels have been shown to reach a peak in the pre-cotyledonary stage, after which a continuous decrease was observed up to the mature stage (Silveira et al., 2008). According to data, AaVicilin and AaLEC-like expression in the Brazilian pine presumes embryo and seed maturation mechanisms to be similar to those observed in other plant species, this depending on $L E C$ TF expression and a fine balance between $\mathrm{ABA}$ and GA (Verdier and Thompson, 2008). 
The primary cell wall of dicot plants is laid down by young cells prior to cessation of elongation and secondary wall deposition. Reversibly glycosylated polypeptides (RGPs), reportedly involved in polysaccharide biosynthesis, seem to play a role in cell-wall biosynthesis, although their precise function remains unknown (Pysh et al., 1999). On cloning a putative RPG-like (AaRPG) from the Brazilian pine in the present study, high levels of transcripts were found, not only during the stages preceding cotyledon elongation and embryo germination, but also in all seed and seedling tissues (Figures 4 and 5). $R P G$ genes are ubiquitously expressed, reaching the highest levels in actively growing tissues. In A. thaliana, RPG1 and 2 have been shown to be required during microspore development and pollen mitosis, conductive to cell division and/or vacuolar integrity (Drakakaki et al., 2006). As to the Brazilian pine, $R P G s$ might present a very similar function to RPG1 and 2, seeing that the pattern of mRNA expression is similar, with a highly conserved sequence protein in plants from different species (Figure S1F).

In summary, we analyzed certain important and conserved plant embryogenesis-related genes that participate in the network that regulates meristem formation and regulation, organ specification, cell fate, and embryo maturation in Brazilian pine. Despite the differences observed during embryogenesis, it was noticed that the differential expression of changes at the transcript level of the analyzed genes is similar to that which occurs in other conifers and angiosperm species. The present results, besides providing a basis for further studies of gene expression during embryogenesis in this gymnosperm, may also become a useful tool in the improvement of an in vitro embryogenesis protocol.

\section{Acknowledgments}

This work was supported by the National Counsel of Technological and Scientific Development (CNPq), through post-doctoral fellowships to P.S.S. (protocol 152306/2007-2) and ALWS (protocol 505071/2008-8).

\section{References}

Aida M and Tasaka M (2006) Genetic control of shoot organ boundaries. Curr Opin Plant Biol 9:72-77.

Alonso-Blanco C, Mendez-Vigo B and Koornneef M (2005) From phenotypic to molecular polymorphisms involved in naturally occurring variation of plant development. Int J Dev Biol 49:717-732.

Altschul SF, Thomas L, Madden A, Schäffer A, Zhang J, Zhang Z, Miller W and Lipman DJ (1997) Gapped BLAST and PSIBLAST: A new generation of protein database search programs. Nucleic Acids Res 25:3389-3402.

Attree SM and Fowke LC (1993) Embryogeny of gymnosperms: Advances in synthetic seed technology of conifers. Plant Cell Tissue Organ Cult 35:1-35.

Astarita LV, Floh EIS and Handro W (2003) Changes in IAA, tryptophan and activity of soluble peroxidase associated with zygotic embryogenesis in Araucaria angustifolia (Brazilian pine). Plant Growth Regul 39:113-118.

Astarita LV, Floh EIS and Handro W (2004) Free amino acid, protein and water content changes associated with seed development in Araucaria angustifolia. Biol Plant 47:53-59.

Bowe LM, Gwénaële C and de Pamphilis CW (2000) Phylogeny of seed plants based on all three genomic compartments: Extant gymnosperms are monophyletic and Gnetales' closest relatives are conifers. Proc Natl Acad Sci USA 97:40924097.

Braybrook SA and Harada JJ (2008) LECs go crazy in embryo development. Trends Plant Sci 13:624-630.

Buchholz JT (1920) Embryo development and polyembryony in relation to the phylogeny of conifers. Am J Bot 7:125-145.

Cairney J, Zheng L, Cowels A, Hsiao J, Zismann V, Liu J, Ouyang S, Thibaud-Nissen F, Hamilton J, Childs K, et al. (2006) Expressed sequence tags from loblolly pine embryos reveal similarities with angiosperm embryogenesis. Plant Mol Biol Rep 62:485-501.

Cairney J and Pullman GS (2007) The cellular and molecular biology of conifer embryogenesis. New Phytol 176:511-536.

Carmell MA, Xuan Z, Zhang MQ and Hannon G (2002) The Argonaute family: Tentacles that reach into RNAi, developmental control, stem cell maintenance and tumorigenesis. Genes Dev 16:2733-2742.

Delgado IJ, Wang Z, de Rocher A, Keegstra K and Raikhel NV (1998) Cloning and characterization of AtRGP1: A reversibly autoglycosylated Arabidopsis protein implicated in cell wall biosynthesis. Plant Physiol 116:1339-1349.

Di Laurenzio L, Wysocka-Diller J, Malamy JE, Pysh L, Helariutta Y, Freshour G, Hahn MG, Feldman KA and Benfey PN (1996) The SCARECROW gene regulates an asymmetric cell division that is essential for generating the radial organization of the Arabidopsis root. Cell 86:423-433.

dos Santos ALW, Silveira V, Steiner N, Vidor M and Guerra MP (2002) Somatic embryogenesis in Parana Pine (Araucaria angustifolia (Bert.) O. Kuntze). Braz Arch Biol Technol 45:97-105.

Drakakaki G, Zabotina O, Delgado I, Robert S, Keegstra K and Raikhel N (2006) Arabidopsis reversibly glycosylated polypeptides 1 and 2 are essential for pollen development. Plant Physiol 42:1480-1492.

Guerra MP, Silveira V, Santos ALW, Astarita LV and Nodari RO (2000) Somatic embryogenesis in Araucaria angustifolia (Bert) O. Ktze. In: Jain S, Gupta P and Newton R (eds) Somatic Embryogenesis in Woody Plants. Kluwer Academic Publishers, Amsterdam, pp 457-478.

Gupta PK and Pullman GS (1991) Method for reproducing coniferous plants by somatic embryogenesis using abscisic acid and osmotic potential variation. US Patent 5:36-37.

Gutierrez L, van Wuytswinkel O, Castelain M and Bellini C (2007) Combined networks regulating seed maturation. Trends Plant Sci 12:294-300.

Kaur D and Bhatnagar SP (1983) Studies in the family Araucariaceae. Beitr Biol Pflanzen 58:369-381.

Kershaw P and Wagstaff B (2001) The Southern conifer family Araucariaceae: History, status and value for paleoenvironmental reconstruction. Annu Rev Ecol Syst 32:397-414.

Kwong RW, Bui AQ, Lee H, Kwong LW, Fischer RL, Goldberg RB and Harada JJ (2003) LEAFY COTYLEDON1-LIKE defines a class of regulators essential for embryo development. Plant Cell 15:5-18. 
Lim J, Helariutta Y, Specht CD, Jung J, Sims L, Bruce WB, Diehn S and Benfey PN (2000) Molecular analysis of the SCARECROW gene in maize reveals a common basis for radial patterning in diverse meristems. Plant Cell 12:13071318 .

Lynn K, Fernandez A, Aida M, Sedbrook J, Tasaka M, Masson P and Barton MK (1999) The PINHEAD/ZWILLE gene acts pleiotropically in Arabidopsis development and has overlapping functions with the ARGONAUTE1 gene. Development $126: 469-481$

Mayer KF, Schoof H, Haecker A, Lenhard M, Jürgens G and Laux T (1998) Role of WUSCHEL in regulating stem cell fate in the Arabidopsis shoot meristem. Cell 95:805-815.

Nardmann J, Reisewitz P and Werr W (2009) Discrete shoot and root stem cell-promoting WUS/WOX5 functions are an evolutionary innovation of angiosperms. Mol Biol Evol 26:1745-1755.

Palovaara J and Hakman I (2008) Conifer WOX-related homeodomain transcription factors, developmental consideration and expression dynamic of WOX2 during Picea abies somatic embryogenesis. Plant Mol Biol 66:533-549.

Preccott A and Martim C (1987) Rapid method for quantitative assessment of levels of specific mRNAs. Plant Mol Biol Report 4:219-224.

Pysh LD, Wysocka-Diller JW, Camilleri C, Bouchez D and Benfey PN (1999) The GRAS gene family in Arabidopsis: Sequence characterization and basic expression analysis of the SCARECROW-LIKE genes. Plant J 18:111-119.

Sarkar AK, Luijten M, Miyashima S, Lenhard M, Hashimoto T, Nakajima K, Scheres B, Heidstra R and Laux T (2007) Conserved factors regulate signalling in Arabidopsis thaliana shoot and root stem cell organizers. Nature 446:811-814.

Schoof H, Lenhard M, Haecker A, Mayer KF, Jürgens G and Laux $\mathrm{T}$ (2000) The stem cell population of Arabidopsis shoot meristems in maintained by a regulatory loop between the CLAVATA and WUSCHEL genes. Cell 100:635-644.

Setoguchi H, Osawa TA, Pintaud J-C, Jaffré T and Veillon J-M (1998) Phylogenetic relationships within Araucariaceae based on rbcL gene sequences. Am J Bot 85:1507-1516.

Silveira V, Santa-Catarina C, Balbuena TS, Moraes FMS, Ricarts CAO, Souza MV, Guerra MP, Handro W and Floh EIS (2008) Endogenous abscisic acid and protein contents during seed development of Araucaria angustifolia. Biol Plant 52:101-104.

Stasolla C, van Zyl L, Egertsdotter U, Craig D, Liu W and Sederoff RR (2003) The effects of polyethylene glycol on gene expression of developing white spruce somatic embryos. Plant Physiol 131:49-60.

Tahir M, Law DA and Stasolla C (2006) Molecular characterization of $P g A G O$, a novel conifer gene of the ARGONAUTE family expressed in apical cells and required for somatic embryo development in spruce. Tree Physiol 26:1257-1270.

Takada S, Hibara K, Ishida $T$ and Tasaka M (2001) The CUPSHAPED COTYLEDON1 gene of Arabidopsis regulates shoot apical meristem formation. Development 128:1127-1135.
Tamura K, Dudley J, Nei M and Kumar S (2007) MEGA 4: Molecular Evolutionary Genetics Analysis (MEGA) software ver. 4.0. Mol Biol Evol 24:1596-1599.

Thompson JD, Gibson TJ, Plewniak F, Jeanmougin F and Higgins DG (1997) The CLUSTAL X windows interface: Flexible strategies for multiple sequence alignment aided by quality analysis tools. Nucleic Acids Res 25:4876-4882.

van Hengel AJ, van Kammen A and de Vries SC (2002) A relationship between seed development, arabinogalactanproteins (AGPs) and the AGP mediated promotion of somatic embryogenesis. Physiol Plant 114:637-644.

Vaucheret H (2007) Plant ARGONAUTES. Trends Plant Sci 13:350-358.

Verdier J and Thompson RD (2008) Transcriptional regulation of storage protein synthesis during dicotyledon seed filling. Plant Cell Physiol 49:1263-1271.

Wan J, Patel A, Mathieu M, Kim S-Y, Xu D and Stacey G (2008) A lectin receptor-like kinase is required for pollen development in Arabidopsis. Plant Mol Biol 67:469-482.

Wu X, Chory J and Weigel D (2007) Combinations of WOX activities regulate tissue proliferation during Arabidopsis embryonic development. Dev Biol 309:306-316.

\section{Internet Resources}

Primer3.0 version 0.4.0 (http://frodo.wi.mit.edu/primer3/).

DNA sequence databases used for comparison, http://www.ncbi.nlm.nih.gov (April 15, 2009).

\section{Supplementary Material}

The following online material is available for this article:

Figure S1A - Alignments of the plant CUC protein family. Multiple alignments were done using ClustalW (ver. 1.74) software.

Figure S1B - Alignments of the plant $W O X$ protein family. Multiple alignments were done using ClustalW (ver. 1.74) software.

Figure S1C - Alignments of the plant $L R R K$ protein family. Multiple alignments were done using ClustalW (ver. 1.74) software.

Figure S1D - Alignments of the plant SCR-like protein family. Multiple alignments were done using ClustalW (ver. 1.74) software.

Figure S1E - Alignments of the plant LEC-like protein family. Multiple alignments were done using ClustalW (ver. 1.74) software.

Figure S1F - Alignments of the plant $R P G$ protein family. Multiple alignments were done using ClustalW (ver. 1.74) software.

This material is available as part of the online article from http://scielo.br/gmb.

Associate Editor: Adriana S. Hemerly

License information: This is an open-access article distributed under the terms of the Creative Commons Attribution License, which permits unrestricted use, distribution, and reproduction in any medium, provided the original work is properly cited. 
Figure S1A

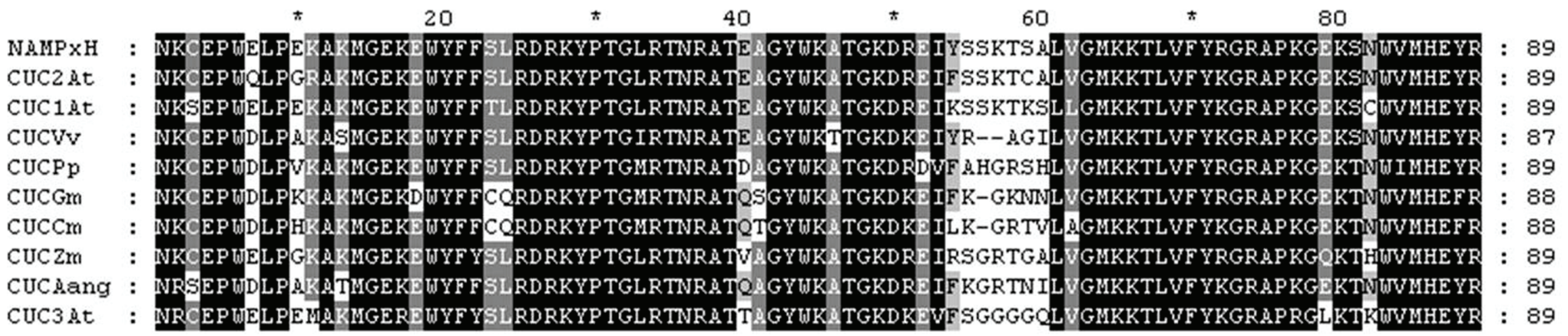

\section{Supplemental figure $1 \mathrm{~A}$ - Alignment of CUC proteins from plants.}

PxH: Petunia $x$ hybrida, NAM-CAA63101;

At: ArabidopsisThaliana, CUC1-NP_188135,CUC2 - NP_200206,CUC3-NP_177768;

Vv: Vitis vinifer a, CUC- CBI15455;

Pp:Pscomitrella patenssubsp. Patens, CUC-XP_001777847;

Gm: Glycine max, CUC- AAX85982;

Cm: Cucurbitamaxima, CUC- ACI01723;

Zm: Zea mays, CUC- ACG42560;

Aang: Araucaria angustifolia, GW924718 
Figure S1B

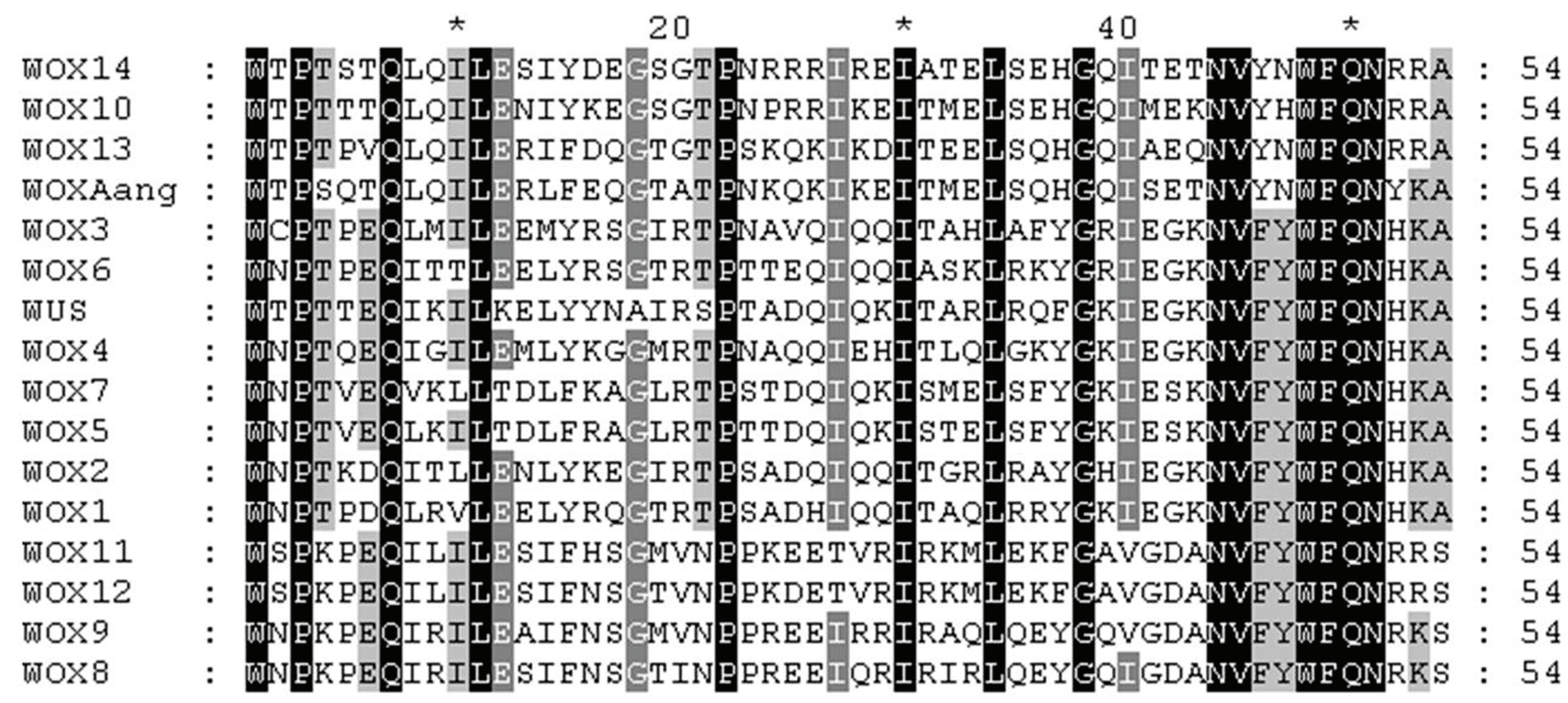

Supplemental figure 1 B - Alignment of WOX proteins from Arabidopsis and Parana pine.

ArabidopsisThaliana acess numbers:

WOX1: Q6X7K0, WOX2: Q6X7K1, WOX3: Q9SIB4, WOX4: Q6X7J9, WOX5:AY25139,

WOX6: Q9SB92, WOX7: Q9FFK0, WOX8: Q6X7J5, WOX9: Q6X7J4,WOX10: Q9LM83,

WOX11: Q6X7J3,WOX12: Q8GY25,WOX13: O81788 and WOX14:

Q9LM84; Aang: Araucaria angustifolia, GW924719 


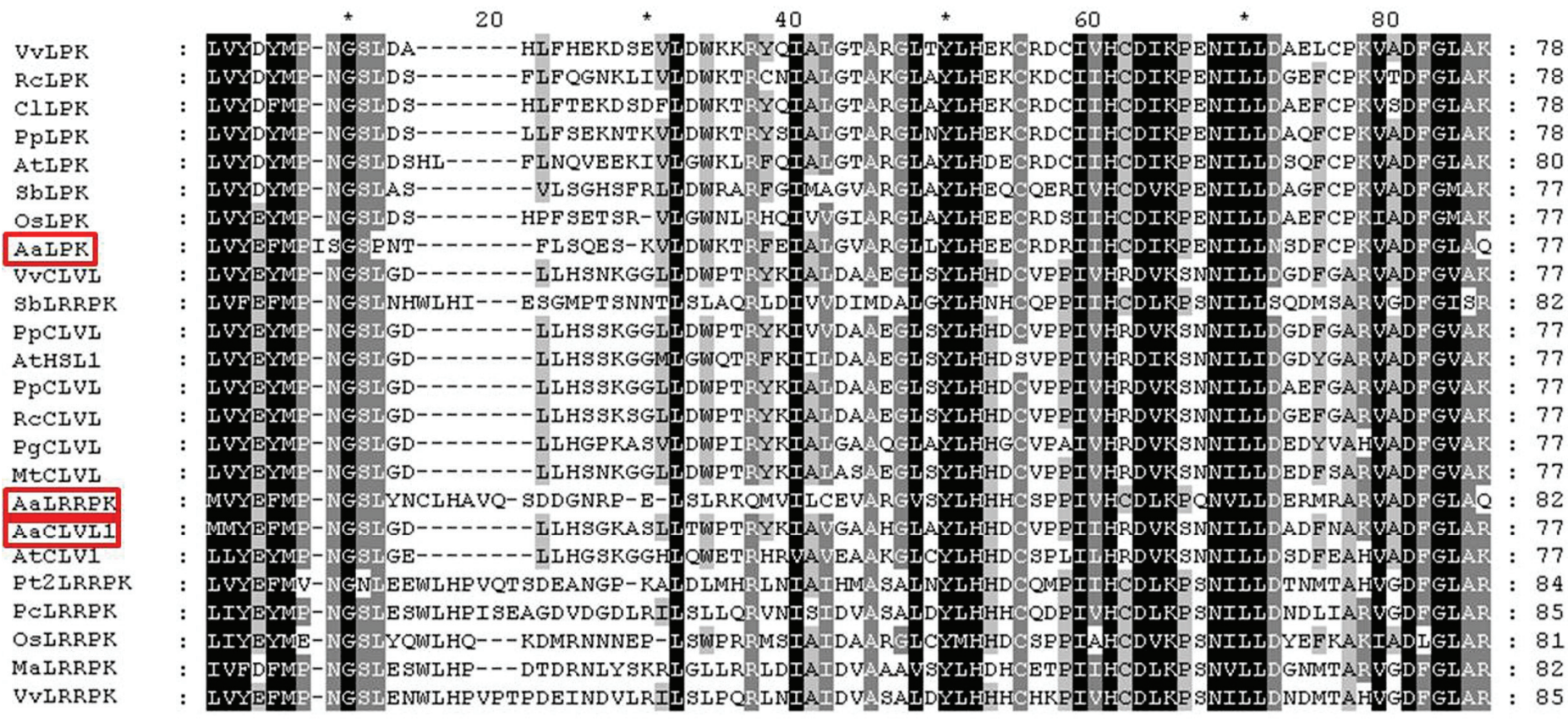

\section{Supplemental figure $1 \mathrm{C}$ - Alignment of LRRK proteins from plants.}

Vv: Vitis vinifera, LPK- XP_002277219, CLVL-CAN77471;

Rc: Ricinus communis, LPK- XP_002529278,CLVL-XP_002517850 ;

Cl: Citrus limon, LPK- ACB45099;

Pp: Populus trichocarpa, LPK- XP_002325680, CLVL - XP_002305776,LRRPK-XP_002329291;

At: ArabidopsisThaliana, LPK - NP_179503, CLV1-NP_17̄7710,HSL1 - NP_177710 ;

Sb: Sorghum bicolor , LPK- XP_002465512,LRRPK-XP_002455198;

Os: Oryza sativa, LPK- BAA94518, LRRPK- EAZ01332;

Pg: Picea glauca, CLVL- ABF73316;

Pc: Prunus cerasus, LRRPK-ABV30769;

Ma: Musa acuminata, LRRPK-ABX56574;

Aa: Araucaria angustifolia. In red squares: LPK: GW924722, CLVL1: GW924723 and LRRPK: GW924717. 


\section{Figure S1D}

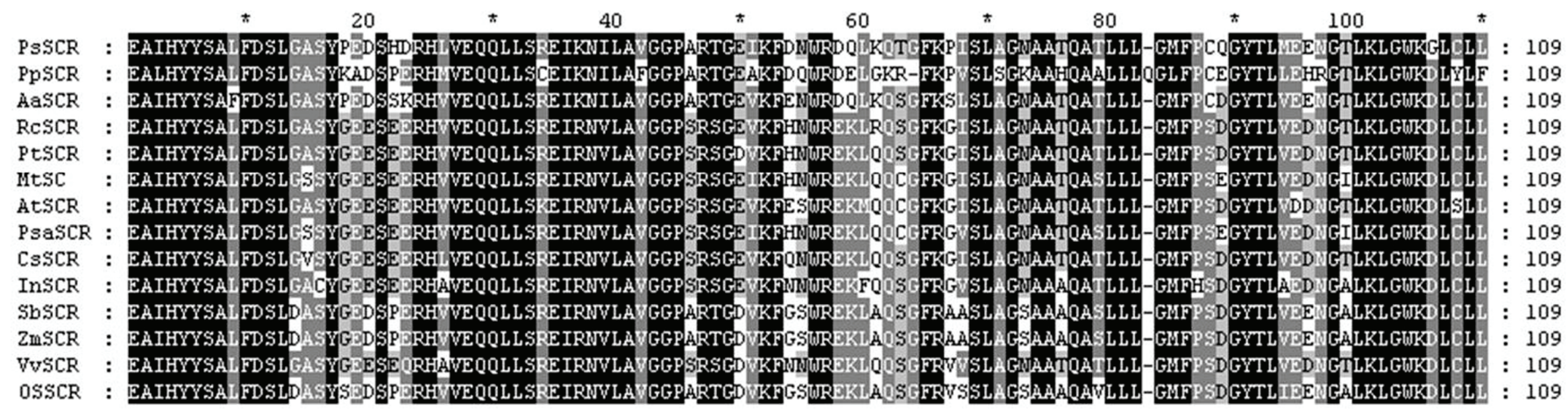

Supplemental figure $1 \mathrm{D}$ - Alignment of SCR-like proteins from plants.

Ps:Pinus sylvestris, SCR-ABH85406;

Pp: Physcomitrella patens subsp. patens, SCR-XP 001786265;

Aa: Araucaria angustifolia, GW924716,

Rc: Ricinus communis, SCR- XP_002519983;

Pt:Populus trichocarpa, SCR-XP_002323112;

Mt:Medicago truncatula,SCR-ABN08308;

At: ArabidopsisThaliana, SCR-AAB06318;

Psa: Pisum sativum, SCR-Q9AVK4;

Cs:Cucumis sativus, SCR-CAI30892;

In:Ipomoea nil, SCR-Q2Z2E9;

Sb: Sorghum bicolor,SCR-XP_002448913;

Zm: Zea mays, SCR-Q9FUZ7;

Vv: Vitis vinifera, SCR -XP_002264349;

Os: Oryza sativa, SCR -BAD 22576 ; 
Figure S1E

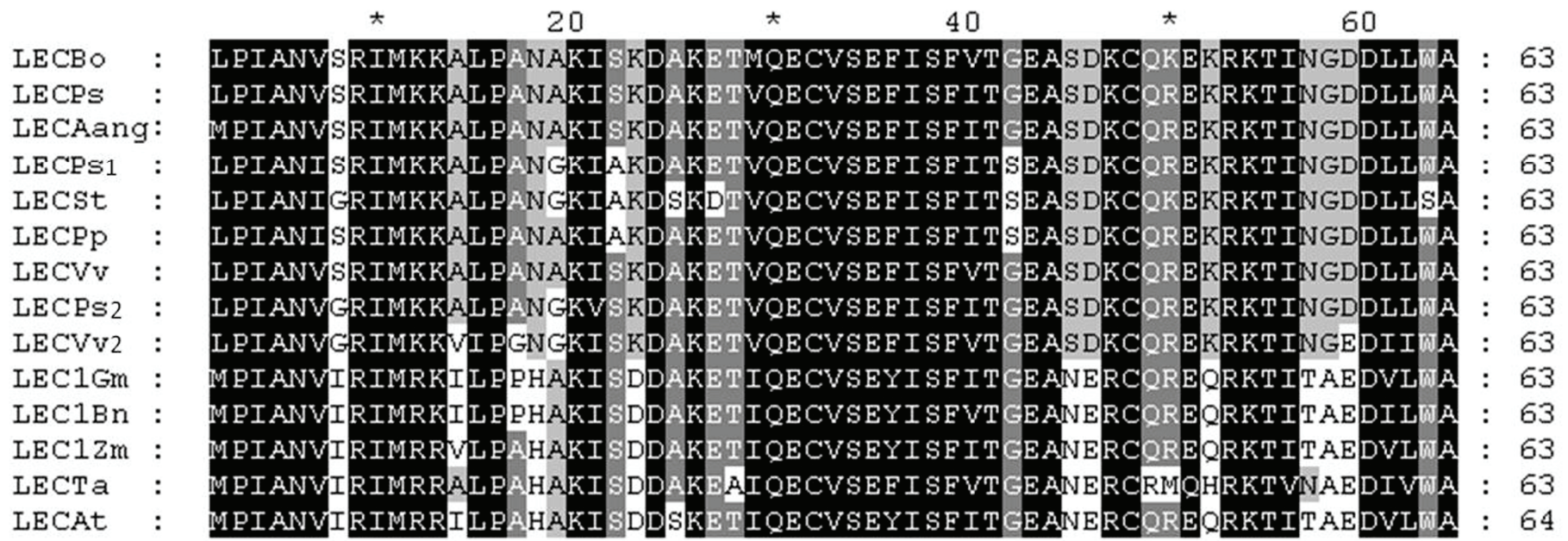

\section{Suplementar figure 1 E - Alignment of LEC-like proteins from plants.}

Bo: Brassica oleracea, LEC - ABD64993

Ps: Picea sitchensis, LEC - ABK21387;

Aa: Araucaria angustifolia, GW924720,

Ps1: Picea sitchensis, LEC - ABK27065;

St: Solanum tuberosum, LEC -;

Pp: Physcomitrella patens subsp. patens, LEC - XP_001757004;

Vv: Vitis vinifera, LEC - CAN70795;

Ps2: Picea sitchensis, LEC - ABK23156;

Vv2: Vitis vinifera, LEC - CAN71881;

Gm: Glycine max, LEC - ABW71514;

Bn:, Brassica napus, LEC - ACB12186;

Zm: Zea mays, LEC - NP_001105518;

Ta:Triticum aestivum, LEC - AAL27661;

At: ArabidopsisThaliana, LEC-NP_199578; 


\section{Figure S1F}

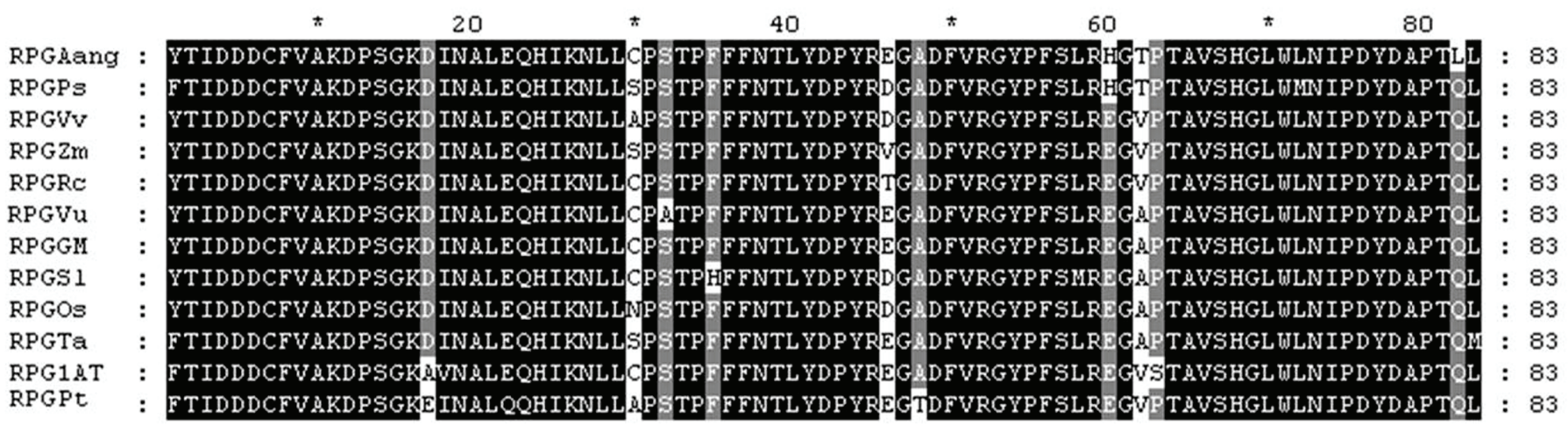

\section{Supplemental figure $1 \mathrm{~F}$ - Alignment of RPG proteins from plants.}

Aang: Araucaria angustifolia, GW924715;

Ps: Picea sitchensis, RPG- ABK21236;

Vv: Vitis vinifera, RPG- CAO62439;

Zm: Zea mays, RPG-ACG33746;

Rc: Ricinus communis, RPG-XP 002514626;

Vu: Vigna unguiculata, RPG-AAB 61672 ;

Gm: Glycine max, RPG-ACU19796;

SI: Solanum lycopersicum, RPG-AAT44738;

Os: Oryza sativa, RPG-NP_001060224;

Ta:Triticum aestivum, RPG-CAA77237;

At: ArabidopsisThaliana, RPG-NP_186872;

Pt:Populus trichocarpa, RPG-XP_002330138 